\title{
Molecular and Evolutionary Analyses of Pseudomonas syringae pv. tomato Race 1
}

\author{
Suparat Kunkeaw, Steven Tan, and Gitta Coaker \\ Department of Plant Pathology, University of California-Davis, Davis 95616, U.S.A.
}

Submitted 4 August 2009. Accepted 13 November 2009.

\begin{abstract}
Pseudomonas syringae pv. tomato, the causal agent of bacterial speck of tomato, has recently become an increasing problem in California due to the evolution and prevalence of highly aggressive race 1 strains. In resistant plant genotypes, the type III effectors AvrPto and AvrPtoB are recognized by the tomato proteins Pto and Prf. We investigated the prevalence of avrPto and avrPtoB in strains collected over the last 13 years in California. All race 1 strains retained avrPtoB but did not express AvrPtoB protein at detectable levels in vitro. However, deletion of avrPtoB indicated that this effector protein is still expressed at low levels in race 1 during infection. avrPto was detected in four race 1 strains but a key amino acid polymorphism prevents this new protein from interacting with and eliciting Pto-mediated resistance. Growth curve analyses demonstrate that this new avrPto allele is still functional and can enhance $P$. syringae virulence on tomato. Multilocus sequence typing was used to resolve phylogenetic relationships and revealed that the majority of race 0 and 1 strains were most closely related to $P$. syringae $\mathrm{T} 1$. Collectively, these data support the hypothesis that existing $P$. syringae populations evolved to overcome genetic resistance by altering the expression and sequence of avrPto and avrPtoB effectors.
\end{abstract}

In order to successfully avoid infection, plants have evolved a series of defense mechanisms that work in concert to limit pathogen invasion and multiplication (Chisholm et al. 2006). Conceptually, there are two primary branches of plant innate immunity. One branch employs extracellular receptors to recognize conserved microbial features, termed pathogen-associated molecular patterns (PAMPs), resulting in PAMP-triggered immunity (PTI) (Chisholm et al. 2006; Jones and Dangl 2006). The second branch uses intracellular plant resistance (R) proteins to recognize pathogen effectors delivered inside host cells during infection, resulting in effector-triggered immunity (ETI) (Chisholm et al. 2006; Jones and Dangl 2006). Bacterial effectors play dual roles in susceptible and resistant genotypes. In the absence of a corresponding $R$ gene, effectors enhance pathogen virulence and are collectively required for pathogenicity (McCann and Guttman 2008). In the presence of a

Corresponding author: G. Coaker; Telephone (530) 752-6541; Fax: (530) 752-5674; E-mail: glcoaker@ucdavis.edu

S. Kunkeaw and G. Coaker contributed equally to this work.

Current address of S. Kunkeaw: Institute of Molecular Biosciences, Manhidol University, Thailand.

* The $e$-Xtra logo stands for "electronic extra" and indicates that Figure 6 appears in color online. corresponding $R$ gene, a particular effector can render the pathogen avirulent. Many type III effectors have been shown to inhibit the function of specific host protein targets which are involved in mediating PTI and ETI defense responses (Zhou and Chai 2008).

Microbial pathogenicity in plants has evolved through an arms race at the molecular level. As microbial pathogens evolve new means to evade defense responses, plants are hypothesized to undergo adaptive evolution, resulting in a continuous battle between plant and pathogen. Insight into how microbial pathogens can evolve to overcome plant innate immunity has come from investigating the molecular basis of resistance breakdown. Studies in bacteria and fungi have demonstrated that pathogen effectors can evade ETI-based resistance through mutations and insertions in the recognized effector, large deletions, and DNA shuffling (Arnold et al. 2007). Wichmann and associates (2005) examined the genetic diversity of the avrBs 2 effector from Xanthomonas campestris, which is recognized by the $B s 2 \mathrm{R}$ gene. Mutations in $a v r B s 2$ included point mutations, frameshifts, and large transposon insertions. A second study analyzed the sequence and function of avrBs 2 from $X$. campestris isolated on $B s 2$ pepper plants (Gassmann et al. 2000). Four mutant $a v r B s 2$ alleles were identified, which possessed small insertions, deletions, and point mutations. Interestingly, avrBs 2 alleles with point mutations still retained their virulence function but only elicited weak recognition by $B s 2$ (Gassmann et al. 2000). Large plasmid deletions were also detected surrounding the Pseudomonas syringae pv. phaseolicola avrPphF effector, which is recognized by the corresponding $R 1$ gene in bean (Rivas et al. 2005). Alterations in AvrXa7's effector gene structure through terminal reassortment or domain swapping can also result in the generation of new specificities (Yang et al. 2005). Taken together, these studies highlight the diverse mechanisms microbial pathogens can employ to evade ETI.

$P$. syringae pv. tomato, the causal agent of bacterial speck of tomato, is one of the most persistent bacterial diseases found in the tomato-growing regions of North America (Goode and Sasser 1980). P. syringae DC3000 can also infect the model plant Arabidopsis, and this pathosystem is widely used to investigate the molecular mechanisms controlling plant innate immunity. In the early 1990s, the tomato Pto gene (for resistance against $P$. syringae pv. tomato) was cloned, which conferred resistance to race 0 (Martin et al. 1993). Pto works in concert with another tomato protein, Prf, to control resistance against bacterial speck (Salmeron et al. 1996). Pto was first introgressed from Solanum pimpinellifolium, a wild tomato species, into tomato cultivars and provided effective disease control for several decades (Pitblado and Kerr 1979, 1980). The unrelated effector proteins AvrPto and AvrPtoB (HopAB2) from $P$. syringae DC3000 induce ETI in resistant tomato geno- 
types (Scofield et al. 1996; Mucyn et al. 2006). Recognition of AvrPto and AvrPtoB culminates in a form of programmed cell death at the site of infection, termed the hypersensitive response (HR), and inhibition of pathogen growth. Pto is a Ser/Thr kinase that directly interacts with both effectors (Scofield et al. 1996; Kim et al. 2002).

Both avrPto and avrPtoB contribute significantly to pathogen virulence, which can explain the historical success of the tomato gene Pto in controlling bacterial speck. Deleting either avrPto or avrPtoB from $P$. syringae DC3000 results in a subtle decrease in virulence, while deleting both genes significantly reduces the pathogenicity of this strain (Lin and Martin 2005). Insights into how avrPto and $a v r P t o B$ act to enhance bacterial virulence by disrupting PTI have been recently discovered in Arabidopsis. AvrPto and AvrPtoB target the receptor-like kinase BAK1, which serves as a signaling partner with both PAMP and brassinosteroid pattern-recognition receptors (Shan et al. 2008). AvrPto and AvrPtoB can also associate with the PAMP receptor FLS2, which acts in concert with BAK1 to detect the presence of the bacterial PAMP flagellin (Shan et al. 2008; Xiang et al. 2008). AvrPto acts as a kinase inhibitor and can inhibit the Pto kinase in vitro (Xing et al. 2007). AvrPtoB's $\mathrm{N}$-terminal domain is required for ETI; its C-terminus is an E3 ubiquitin ligase and is required for its virulence and anti-programmed cell death functions (Abramovitch et al. 2003, 2006; Janjusevic et al. 2006). Recently, it has been shown that AvrPtoB ubiquitinates FLS2, targeting it for degradation (Göhre et al. 2008). Taken together, these results highlight the importance of AvrPto and AvrPtoB in inhibiting PTI through their PAMP receptor and co-receptor targets.

The purpose of this study was to investigate the molecular basis of resistance breakdown in $P$. syringae strains collected in Northern California over the last decade. Our results indicate that current $P$. syringae strains obtained from infected tomato plants are all race 1 and can defeat Pto-mediated resistance, and most exhibit increased virulence compared with laboratory strains. Multilocus sequence typing (MLST) has revealed that the majority of strains are very closely related $P$. syringae $\mathrm{T} 1$ and possess identical sequence types. We also investigated the function and prevalence of the avrPto and $a v r P t o B$ effectors. Collectively, these data indicate that the $P$. syringae population in California has evolved to overcome Ptomediated resistance by altering the expression and sequence of the AvrPto and AvrPtoB effectors as well as acquiring novel virulence factors.

\section{RESULTS}

\section{Recent $\boldsymbol{P}$. syringae strains isolated in California are race 1 and exhibit enhanced virulence on tomato.}

In order to gain a more complete understanding of the genetic and phenotypic diversity of a collection of $P$. syringae pv. tomato strains, we investigated the population structure and virulence of strains collected throughout California over the last 13 years. The first report of race 1 strains detected in California occurred with the identification of $P$. syringae A9, collected in 1996 (Table 1) (Arredondo and Davis 2000). In 2005, there was an outbreak of bacterial speck of tomato in California and the vast majority of strains collected from 2005 to 2007 were race 1 (M. Davis, personal communication). We were unable to identify any race 0 strains in 2007, 2008, or 2009 from infected tomato plants in the field. Individual colonies were isolated from infected tomato leaves and tested for fluorescence on King's B (KB) media. Purified strains were then tested for their virulence and infectivity on the tomato line Rio-Grande 76R (Pto/Pto Prf/Prf) and the Rio-Grande 76R pto mutant (ptoll/pto11 Prf/Prf (Table 1). Race 0 strains, such as $P$. syringae DC3000, are recognized by Pto in RioGrande 76R and can only cause disease on Rio-Grande 76R ptoll. In contrast, race 1 strains can avoid Pto-mediated resistance and cause disease on both Rio-Grande $76 \mathrm{R}$ and $76 \mathrm{R}$ pto11. We found that 16 of the 17 race 1 strains were as virulent or more virulent than $P$. syringae T1, a well-characterized race 1 strain frequently used in the laboratory, by visual analysis of disease symptoms (Table 1) (Almeida et al. 2009). Growth curve analyses on Rio-Grande 76R demonstrated that multiple California strains can grow to significantly higher levels (8- to 13-fold) than $P$. syringae $\mathrm{T} 1$ and cause more disease symptoms (Fig. 1A and B). We also investigated bacterial aggressiveness on the processing $\mathrm{cv}$. AB 2. AB 2 is currently the most popular processing cultivar in California, accounting for $15.4 \%$ of processing loads in 2008 (California Processing Tomato Advisory Board). P. syringae strains A9, 838-16, and 19 all displayed enhanced disease symptoms on $\mathrm{AB} 2$, indicating that these strains are also hypervirulent on common tomato cultivars (Fig. 1C).

Table 1. Pseudomonas syringae strains isolated in California differ in virulence and the presence of individual effectors ${ }^{\mathrm{a}}$

\begin{tabular}{|c|c|c|c|c|c|c|c|}
\hline Strain & County isolated & Year & avrPto & avrPtoB & Virulence, tomato & Virulence, Arabidopsis & Coronatine production \\
\hline 315 & San Benito & 1998 & - & + & $\mathrm{nt}$ & $\mathrm{nt}$ & $\mathrm{nt}$ \\
\hline 316 & Yolo & 1998 & + & + & $\mathrm{nt}$ & $\mathrm{nt}$ & $\mathrm{nt}$ \\
\hline A9 & Yolo & 1996 & - & + & Hypervirulent & - & ++ \\
\hline 407 & Sacramento & 1997 & - & + & Virulent & - & + \\
\hline $838-16$ & Yolo & 2005 & + & + & Hypervirulent & - & + \\
\hline $836-2$ & Yolo & 2005 & - & + & Hypervirulent & - & ++ \\
\hline $838-6$ & San Joaquin & 2005 & - & + & Virulent & - & ++ \\
\hline $838-8$ & San Joaquin & 2005 & + & + & Hypervirulent & - & ++ \\
\hline $838-9$ & San Joaquin & 2005 & - & + & Virulent & - & + \\
\hline $838-4$ & Colusa & 2005 & - & + & Hypervirulent & - & +++ \\
\hline 16 & Yolo & 2008 & - & + & Hypervirulent & - & + \\
\hline 24 & Yolo & 2008 & + & + & Virulent & - & + \\
\hline 410 & Yolo & 2008 & - & + & Hypervirulent & - & - \\
\hline 22 & Sacramento & 2008 & + & + & Hypervirulent & - & +++ \\
\hline 23 & Sacramento & 2008 & - & + & Virulent & - & + \\
\hline 20 & Kern & 2008 & - & + & Virulent & - & - \\
\hline 21 & Kern & 2008 & - & + & Hypervirulent & - & - \\
\hline 18 & Kern & 2008 & - & + & Weakly virulent & - & - \\
\hline 19 & Kern & 2008 & - & + & Hypervirulent & - & ++ \\
\hline
\end{tabular}

${ }^{a}$ Virulence was determined by bacterial growth curves and visually inspecting disease symptoms following bacterial inoculation. Strains 315 and 316 are race 0 . All other strains are race 1 and their virulence was compared with that of P. syringae T1 on Solanum lycopersicum cvs. Rio-Grande 76R and the pto mutant 76R pto11. All strains tested were not able to infect Arabidopsis rps 2-101 c/rpm1-3; $\mathrm{nt}=\mathrm{not}$ tested. 
We also investigated individual strains for their ability to infect Arabidopsis and produce the toxin coronatine. Surprisingly, we found that coronatine production differed among strains and the ability to produce coronatine did not correlate with enhanced virulence on tomato (Table 1). We used P. syringae DC3000 as a positive control for coronatine production. The coronatine mutant, $P$. syringae DC3000 cor- (Sreedharan et al. 2006), and $P$. syringae $\mathrm{T} 1$ were used as negative controls in our coronatine production assay. Because coronatine is an important phytotoxin involved in overcoming the plant innate immune system (Nomura et al. 2005; Sreedharan et al. 2006), these results suggest that certain strains have most likely acquired novel virulence factors, including toxins. We also found that none of the race 1 strains could induce disease symptoms in Arabidopsis after syringe infiltration (Table 1). We used the Arabidopsis Col0 rps2-101c/rpm1-3 mutant for infection assays in order to decrease the chance of ETI-mediated recognition. Growth curve analyses demonstrated that the strains $P$. syringae A9, 838-16, and 19 could not cause disease on Arabidopsis (Fig. 1D and E). To date, only P. syringae DC3000 can infect Arabidopsis, while all other tested Pseudomonas strains isolated from tomato cannot (Yan et al. 2008; Almeida et al. 2009).

\section{Phylogenetic characterization}

of $P$. syringae strains isolated in California.

In order to investigate the relationship between $P$. syringae strains isolated in California and other closely related $P$. syringae pathovars, we performed MLST, a typing method for the characterization of bacterial strains by examining the nucleotide sequence of multiple housekeeping genes, or fragments of them, for evolutionary and population genetics analyses (Maiden et al. 1998). We sequenced portions of seven core genome genes that have been previously demonstrated to be useful in elucidating $P$. syringae phylogeny ( $g a p 1$ rpoD pgi gyrB kup acnB, and gltA) (Sarkar and Guttman 2004; Yan et al. 2008). We included the gene sequences of closely related $P$. syringae strains previously described by Yan and colleagues in our analyses (Yan et al. 2008). All strains belonging to each sequence type are listed in Table 2 . The sequences of the seven genes of each sequence type were concatenated and a maximum likelihood tree and a neighbor-joining tree were constructed and rooted with the sequence of $P$. syringae pv. syringae B728A (Fig. 2). The neighbor-joining tree (Fig. 2) and the maximum likelihood tree (not shown) had the same overall topology and possessed similar branch lengths.

Of the 17 race 1 California strains analyzed, 16 possessed identical sequence types. Phylogenetic analyses indicate that these 16 California strains possessed the same sequence type as $P$. syringae T1 (Table 2; Fig. 2). The majority of $P$. syringae strains characterized to date possess identical sequence types

Fig. 1. Pseudomonas syringae pv. tomato strains isolated in California are race 1 and are hypervirulent compared with $P$. syringae T1. A, Four-weekold Rio Grande 76R tomato plants were dip inoculated with different $P$. syringae strains and subjected to growth curves 0 and 4 days post inoculation. Dip inoculations were performed at a concentration of $1 \times 10^{7}$ $\mathrm{CFU} / \mathrm{ml}$. Results are shown as the mean $(n=4)$, including standard deviation. Statistical differences were detected by Fisher's least significant difference, $\alpha=0.05$ (Snedecor and Cochran 1980). B, Disease symptoms 4 days post inoculation on Rio Grande 76R. C, Disease symptoms 4 days post inoculation on the processing cv. AB 2. D, P. syringae strains cannot infect Arabidopsis. Four-week-old Arabidopsis rps2-101c/rpm1-3 plants were inoculated by syringe infiltration with different $P$. syringae strains. Syringe inoculations were performed at a concentration of $0.5 \times 10^{5}$ $\mathrm{CFU} / \mathrm{ml}$. Results are shown as the mean $(n=4)$, including standard deviation. Statistical differences were detected with a two-tailed $t$ test ( $\alpha=$ 0.001). E, Arabidopsis disease symptoms 4 days post inoculation. with either $P$. syringae T1 or $P$. syringae JL1065 (Yan et al. 2008). Interestingly, $P$. syringae 18 was most closely related to strains of $P$. syringae pv. apii (Pap), which were isolated from celery. Previously, Yan and colleagues (2008) found that Pap1089 was unable to infect the $S$. lycopersicum cv. SunPride based on visual inspection of disease symptoms. However, some $P$. syringae pv. apii can infect both celery and tomato (B. Vinatzer, personal communication). Although $P$. syringae 18 is the least virulent of the strains collected in California, we were still able to detect bacterial speck disease symptoms on the tomato genotypes Rio-Grande 76R and 76R pto11. Growth
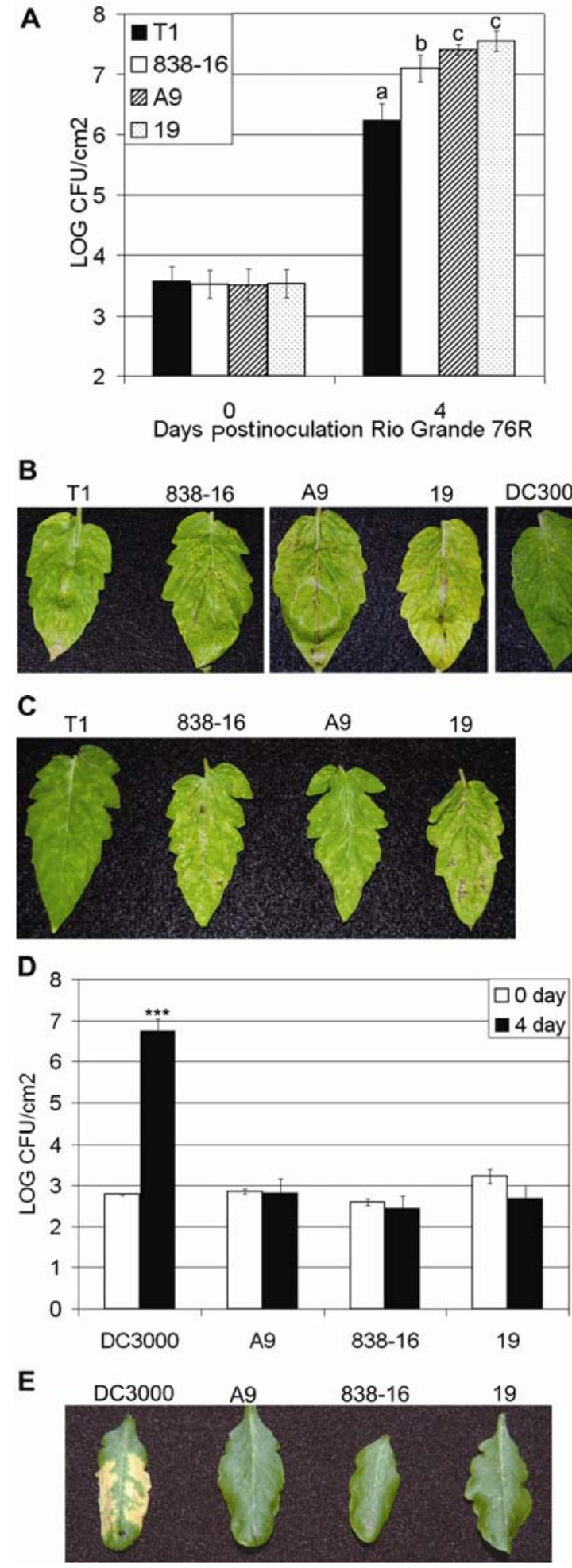
curve analyses with $P$. syringae 18 were also performed on Rio-Grande 76R and 76R ptoll. P. syringae 18 is able to grow approximately $1.7 \mathrm{log}$ in both tomato genotypes, indicating that this strain can, indeed, infect tomato and is race 1 (data not shown).

We also included two $P$. syringae race 0 strains, 315 and 316, in our MLST analyses (Table 1; Fig. 2). Interestingly, both strains were closely related to $P$. syringae T1. $P$. syringae 316 possessed a sequence type identical to T1, while strain 315 differed by a single nucleotide polymorphism in the $p g i$ allele (Fig. 2). The observation that both P. syringae strains 315 and 316 possess MLST profiles similar to all other California strains suggests that race 1 strains either recently evolved from existing $P$. syringae populations due to widespread cultivation of cultivars possessing Pto or have been historically present at low levels in the pathogen population.

\section{$P$. syringae strains isolated in California have evolved to overcome Pto-mediated resistance in tomato by altering the expression, sequence, and prevalence of AvrPto and AvrPtoB.}

Previous reports have shown that avrPto and avrPtoB contribute significantly to Pto virulence on susceptible tomato cultivars (Lin and Martin 2005). The majority of the California race 1 strains tested were more virulent, growing 8- to 13 -fold more than previously characterized $P$. syringae strains. In order to investigate the prevalence and function of avrPto and $a v r P t o B$ in this population, we sequenced and analyzed the expression pattern of both effectors. We found that 4 of the 17 race $1 P$. syringae strains possessed avrPto (Table 1). The avrPto genes in the California race 1 strains were identical and possessed five amino acid polymorphisms when compared with the DC3000 allele. Fifteen race 1 avrPtoB homologs were nearly identical to $\operatorname{avrPtoB}$ from $\mathrm{T} 1\left(A v r P t o B_{\mathrm{T} 1}\right)$, with only one polymorphism that changed that amino acid at position 6 from a glycine to an arginine. These effector homologs will be referred to as $a_{v r P t o_{838-16}}$ and $a v r P t o B_{19}$ throughout the remainder of this article and were named after the strain from which they were first identified (Table 1). We also sequenced one $a v r P t o B$ homolog from strain 18 that was related to a partial sequence of avrPtoB from $P$. syringae pv. thea, the causal agent of black rot of tea. However, avrPto $B_{18}$ possessed a single base pair insertion near the $5^{\prime}$ end of the gene, rendering it nonfunctional.

Next, we investigated whether $a v r P t o_{838-16}$ and $a v r P t o B_{19}$ are expressed. Culturing gram-negative plant-pathogenic bacteria at low temperature and low $\mathrm{pH}$ in minimal media mimics infection conditions and induces effector expression as well as secretion (Huynh et al. 1989). P. syringae strains were cultured in minimal media and separated into cell and supernatant fractions. The cellular fraction was used to analyze avrPto and $a v r P t o B$ expression at the RNA and protein level. We were able to detect the expression of both homologs by reverse-transcriptase polymerase chain reaction (RT-PCR), indicating that these are functional genes whose expression is most likely induced during infection (Fig. 3A). AvrPto ${ }_{838-16}$ is also expressed and secreted by the T3SS (Fig. 3B). We could not detect protein-level expression of $\mathrm{AvrPtoB}_{19}$ or $\mathrm{AvrPtoB}_{\mathrm{T} 1}$ (Fig. 3B). Previously, Lin and Martin (2007) showed that avrPtoB $B_{\mathrm{T} 1}$ was expressed at the RNA level but the protein did not accumulate in $P$. syringae $\mathrm{T} 1$ when grown in minimal media (Lin and Martin 2007). These results demonstrate that modulating AvrPtoB expression is a common mechanism used by multiple race 1 strains to overcome Pto-mediated resistance.

Although we were unable to detect $\mathrm{AvrPtoB}_{19}$ protein expression by Western blot under laboratory conditions, it is still

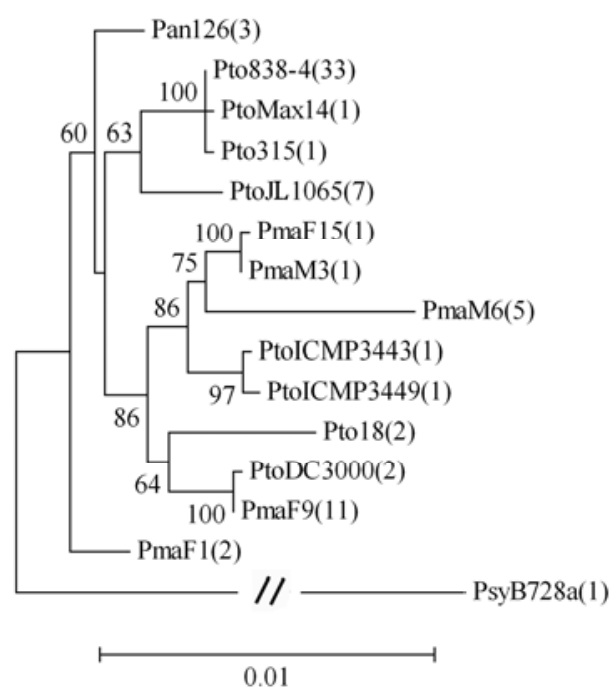

Fig. 2. Neighbor-joining tree of concatenated DNA fragments. Representative strains for each sequence type (ST) are shown and the number of strains belonging to each ST is indicated in parentheses. Pseudomonas syringae pv. syringae $\mathrm{B} 728 \mathrm{~A}$ (PsyB728A) was used as the outgroup. Pto $=P$. syringae pv. tomato, $\mathrm{Pan}=P$. syringae $\mathrm{pv}$. antirrhini, $\mathrm{Pma}=P$. syringae pv. maculicola , and Psy = P. syringae pv. syringae.

Table 2. Sequence types (ST) of strains used in this study ${ }^{\mathrm{a}}$

\begin{tabular}{ll}
\hline ST number & \multicolumn{1}{c}{ Isolates } \\
\hline 1 & Pan126, Pan152E, Pan4303 \\
3 & PtoT1, PtoMax1, PtoMax13, PtoPST6, PtoPT13, PtoPT14, PtoPT18, PtoPT2, PtoPT21, PtoPT26, PtoPT32, PtoNCPP1108, PtoB181, \\
& Pto1318, Pto487, PtoKS127, Pto838-4, Pto838-6, Pto838-8, Pto838-9, Pto838-16, Pto836-2, PtoA9, Pto407, Pto410, Pto16, Pto19, \\
& Pto20, Pto21, Pto22, Pto23, Pto24 \\
4 & PtoMax14 \\
5 & PtoJL065, PtoJL1031, PtoPT28, PtoPT29, PtoPT30, PtoPST26L, PtoKS112 \\
6 & PmaF1, PmaF7 \\
7 & Pap1089, Pto18 \\
8 & PmaF15 \\
9 & PmaM3 \\
10 & PmaM6, PmaM1, PmaM2, PmaM8, Pma1766 \\
11 & PtoICMP3443 \\
12 & PtoICMP3449 \\
13 & PtoDC3000, PtoOH314 \\
14 & PmaF9, PmaF6, PmaF10A, PmaF16, PmaF17, PmaF18, PmaF19, Pma84-59, PmaICMP3435, PmaICMP3455, PmaICMP9305 \\
15 & Pto315 \\
16 & PsyB728a
\end{tabular}

${ }^{a}$ All other Pseudomonas syringae strains and ST have been described previously (Yan et al. 2008). Pto $=$ P. syringae pv. tomato, Pan $=P$. syringae pv. antirrhini, $\mathrm{Pma}=P$. syringae pv. maculicola, $\mathrm{Pap}=P$. syringae $\mathrm{pv}$. apii, and Psy $=P$. syringae pv. syringae . 
possible that AvrPtoB $_{19}$ proteins are weakly expressed during infection and contribute to pathogen virulence or avirulence. After conducting plant inoculations with multiple race 1 strains, we observed that those strains grew four- to sevenfold more on the Rio-Grande 76R pto11 genotype than 76R, although these two tomato cultivars are near-isogenic lines (Fig. 4A). This observation supports the hypothesis that $\mathrm{AvrPtoB}_{19}$ protein may still be expressed at a low level during infection. In order to test this hypothesis, two independent $P$. syringae $19 \Delta$ avrptob knockout mutants were generated and subjected to growth curve analyses on Rio-Grande 76R and 76R ptoll. P. syringae 19 $\Delta$ avrptob grows to equal levels on $76 \mathrm{R}$ and $76 \mathrm{R}$ pto11, whereas wild-type $P$. syringae 19 exhibited more growth on 76R ptoll than 76R (Fig. 4). These results suggest that a small amount of the AvrPtoB effector is delivered into plant cells by race 1 strains. We were also able to detect a decrease in virulence of 1.5- to 4-fold on P. syringae 19 savrptob knockouts when compared with $P$. syringae 19 inoculated on Rio Grande 76R ptoll across multiple experiments. However, the statistical significance of this trend varied from experiment to experiment.

Our analysis of different race 1 strains collected in California revealed that four race 1 strains possess AvrPto ${ }_{838-16}$, a novel homolog that is expressed and secreted via the T3SS (Table 2; Fig. 4). There are five amino acid polymorphisms between AvrPto $_{\mathrm{DC} 3000}$ and AvrPto $_{838-16}$ (Fig. 5A). Previously, AvrPto ${ }_{\mathrm{DC} 3000}$ was shown to interact with tomato Pto by yeast two-hybrid analysis (Scofield et al. 1996; Tang et al. 1996). The co-crystal structure of AvrPto $_{\mathrm{DC} 3000}$ in complex with Pto has also been published (Xing et al. 2007). This structural analysis revealed that AvrPto ${ }_{\mathrm{DC} 3000}$ directly interacts with Pto at two interfaces: i) one end of an AvrPto helical bundle (Y89, M90, L101, and P102) with one Pto loop preceding $\beta 1$, and ii) the AvrPto GINP motif with the Pto P+1 loop (Xing et al. 2007). AvrPto $_{838-16}$ contains a point mutation in its GINP loop (G95E) when compared with AvrPto $_{\mathrm{DC} 3000}$ (Fig. 5A). This region of the protein mediates contact with Pto and is required for Pto-mediated resistance in DC3000 (Wulf et al. 2004; Xing et al. 2007). We hypothesized that AvrPto 838-16 is no longer recognized by Pto due to the G95E substitution. In support of this hypothesis, the AvrPto allele from race 0 strain 316 possesses a glycine at position 95 but retains all four other polymorphisms present in AvrPto $_{838-16}$ (Fig. 5A). In order to investigate whether AvrPto $_{838-16}$ is still able to interact with Pto, we performed yeast two-hybrid analysis. As expected, we were able to detect a robust interaction between Pto, AvrPto ${ }_{\mathrm{DC} 3000}$, and the AvrPto ${ }_{838-16}$ (E95G) mutant by yeast two-hybrid analysis. However, we were not able to detect an interaction between Pto and AvrPto ${ }_{838-16}$ by yeast two-hybrid analysis, indicating that Pto cannot interact with AvrPto ${ }_{838-16}$ due to a mutation in its GINP loop (Fig. 5D). All AvrPto alleles are expressed at similar levels in yeast (Fig. 5E).

We also investigated whether AvrPto $_{838-16}$ could be recognized by Pto and Prf when expressed using Agrobacterium-mediated transient expression. As expected, transient expression of AvrPto $_{\mathrm{DC} 3000}$ resulted in a robust hypersensitive response (HR) $30 \mathrm{~h}$ post infiltration on Rio Grande 76R but not 76R ptoll (Fig. 5B). Transient expression of AvrPto $_{838-16}$ did not induce an HR in Rio Grande 76R but transient expression of
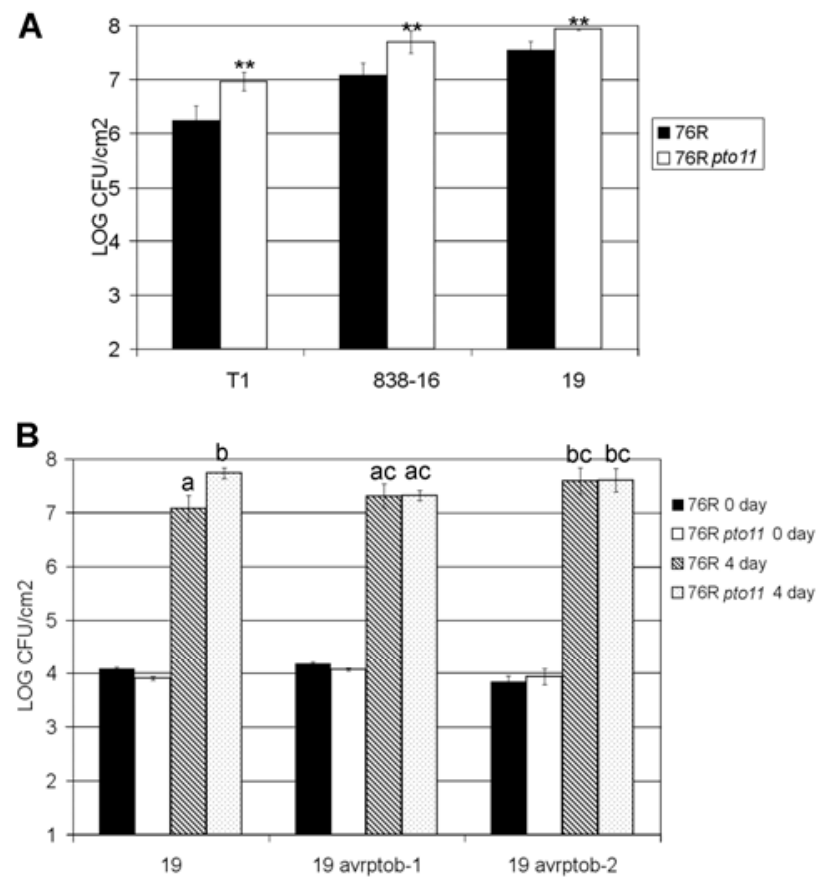

Fig. 4. Pseudomonas syringae $19 \Delta a v r p t o b$ knockout grows to similar levels on Rio-Grande 76R and 76R pto11. A, P. syringae race 1 strains are less virulent on tomato genotypes possessing Pto-mediated resistance. Four-week-old Rio-Grande 76R and 76R ptoll plants were dip inoculated and growth curves conducted 4 days post inoculation. Results are shown as the mean $(n=4)$, including standard deviation. B, P. syringae 19 $\Delta a v r p t o b$ knockout grows to similar levels on Rio-Grande 76R and 76R pto11. Results from two independent knockout lines are shown. Dip inoculations were performed at a concentration of $1 \times 10^{7} \mathrm{CFU} / \mathrm{ml}$. Results are shown as the mean $(n=4)$, including standard deviation. Statistical differences were detected by Fisher's least significant difference, $\alpha=0.05$ (Snedecor and Cochran 1980).

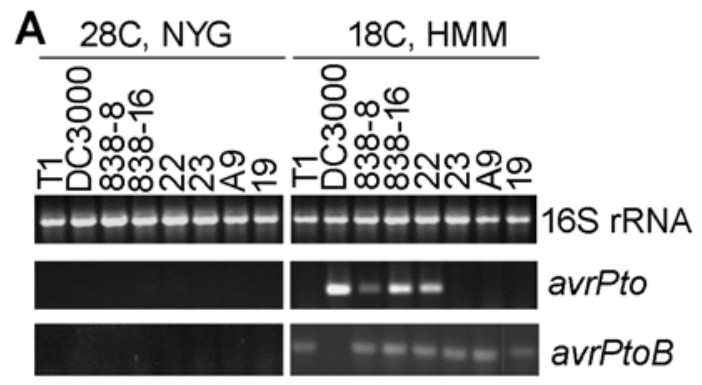

B

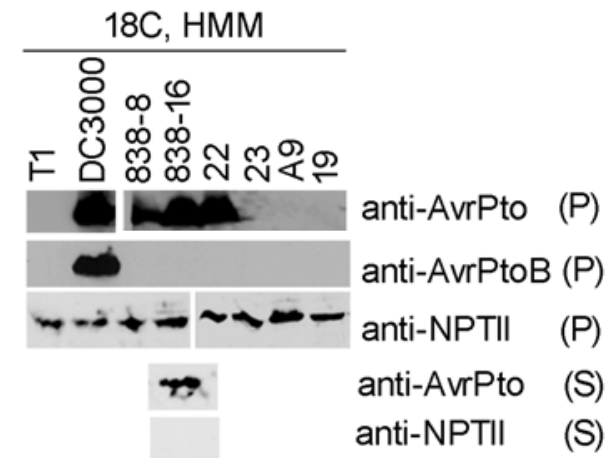

Fig. 3. Expression of AvrPto and AvrPtoB in Pseudomonas syringae strains by reverse-transcriptase polymerase chain reaction (RT-PCR) and immunoblot. Bacteria were grown in rich (NYG) or minimal (HMM) media. RNA was extracted from bacterial pellets. Protein extracts were analyzed from bacterial pellets (P) and culture supernatant (S). A, avrPtoB and avrPto alleles are expressed at the RNA level in California race 1 strains. RNA was isolated and subjected to RT-PCR. AvrPtoB primers were designed to only detect race 1 alleles (T1 and 19). B, AvrPto protein is expressed in California race 1 strains and AvrPto from isolate $838-16$ is secreted by the type III secretion system. However, AvrPtoB protein expression is not detectable in race 1 strains. Proteins were subjected to an anti-AvrPto, anti-AvrPtoB, and anti-NPTII immunoblots. NPTII is a soluble, unsecreted protein. 
AvrPto $_{838-16}$ (E95G) did induce an HR (Fig. 5B). Western blots were conducted to verify that both genes were expressed using transient expression in Nicotiana benthamiana. $N$. benthamiana was used to detect protein expression because infiltration of tomato with Agrobacterium species at an optical density at $600 \mathrm{~nm}\left(\mathrm{OD}_{600}\right)$ over 0.1 induced an HR due to PTI, making it difficult to detect transient protein expression by Western blot in tomato. We were able to detect expression of all AvrPto alleles (Fig. 5C). Taken together, these results indicate that AvrPto $_{838-16}$ can no longer interact with Pto due to a single amino acid change in the GINP loop to EINP and, as a result, can no longer elicit Pto-mediated resistance.

In order to determine whether avrPto $_{838-16}$ can still confer a virulence advantage, we expressed this effector in $P$. syringae
19 avrptob-1 and conducted growth curves on tomato Rio Grande 76R ptoll. Both $a_{v r P t o}{ }_{838-16}$ and $a^{2 v r P t o_{\mathrm{DC} 3000}}$ enhanced P. syringae 19 avrptob- 1 virulence (Fig. $6 \mathrm{~A}$ and $\mathrm{B}$ ). P. syringae 19 avrptob-1 expressing either avrPto allele grew sevenfold more on Rio Grande 76R ptoll and exhibited more severe disease symptoms. These results indicate that avrPto $_{838-16}$ can still promote bacterial virulence on tomato.

\section{DISCUSSION}

How has the $P$. syringae population in California evolved to overcome Pto-mediated resistance in tomato? For over 20 years, genetic resistance conferred by the tomato genes Pto and Prf has been deployed to help control bacterial speck disease pressure

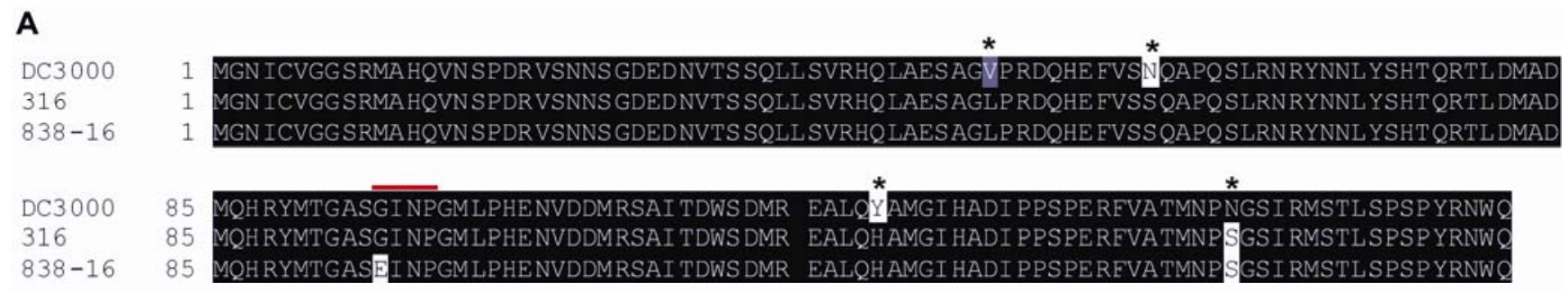

B $\quad 76 \mathrm{R}$

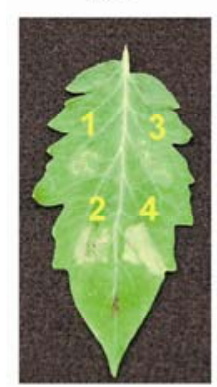

D

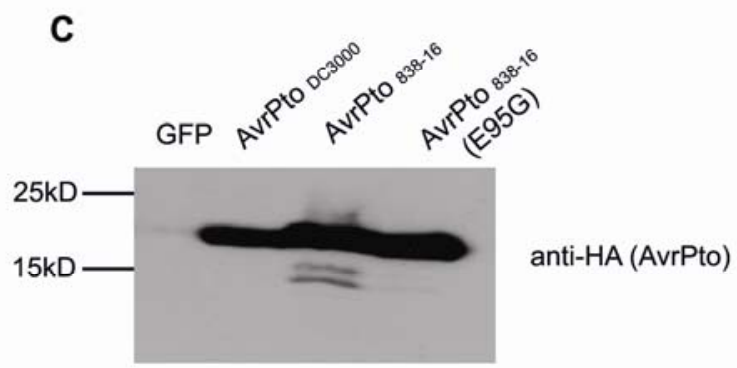

$76 \mathrm{R}$ pto11

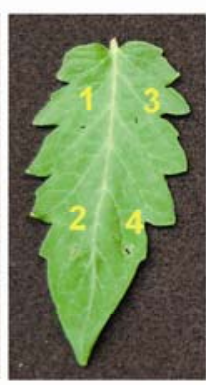

C

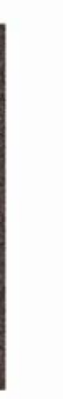

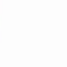

$\begin{array}{cc}\mathrm{SD}-2+ & \mathrm{SD}-3+ \\ \text { a-gal } & 10 \mathrm{mM} 3 \mathrm{AT}\end{array}$
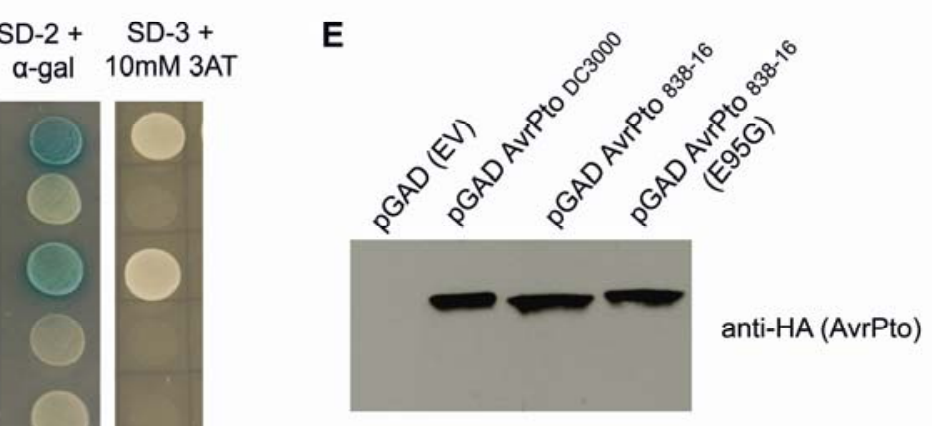

AvrPto $_{838-16}$ (E95G) pGAD + pGBD (EV)

$$
\begin{array}{r}
\operatorname{pGAD}(E V)+\text { Pto pGBD } \\
+ \text { control } \\
\operatorname{pGAD}(E V)+\text { pGBD }(E V)
\end{array}
$$

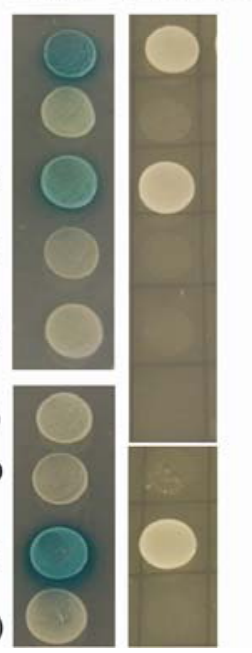

Fig. 5. A novel avrPto allele present in Pseudomonas syringae race 1 isolates is no longer recognized in tomato. A, Clustal W alignment of AvrPto from $P$. syringae DC3000 (race 0), P. syringae 316 (race 0), and P. syringae 838-16 (race 1). B, AvrPto $838-16$ is no longer recognized by Pto and does not elicit a Ptodependent hypersensitive response in tomato due to the presence of a glutamic acid (E) residue at position 95. Agrobacterium spp.-mediated transient expression of AvrPto:HA $\mathrm{DC}_{3000}$ AvrPto:HA $\mathrm{H}_{88-16}$, and AvrPto:HA $\mathrm{H}_{83-16}$ (E95G) in Rio-Grande 76R and 76R pto11 plants. Agrobacterium sp. was infiltrated at an optical density at $600 \mathrm{~nm}\left(\mathrm{OD}_{600}\right)=0.1$ and the picture taken $24 \mathrm{~h}$ post infiltration; $1=$ pMD1 GFP, $2=$ AvrPto:HA $\mathrm{HC}_{0000}, 3=\mathrm{pMD}$ AvrPto:HA $\mathrm{H}_{838-16}, 4=$ AvrPto:HA $\mathrm{H}_{838-16}$ (E95G). C, Western blot verifying expression of AvrPto:HA alleles in Nicotiana benthamiana. Agrobacterium sp. was infiltrated at an OD $600=$ 1.0 and samples were taken $40 \mathrm{~h}$ post infiltration. D, AvrPto ${ }_{838-16}$ no longer interacts with Solanum pimpinellifolium Pto by yeast two-hybrid analysis. EV $=$ empty vector; $\mathrm{pGAD}=$ pGADT7 activation domain vector; $\mathrm{pGBD}=$ pGBDKT7 DNA binding domain vector; SD-2 = synthetic dextrose media lacking leucine and tryptophan; and SD-3 = synthetic dextrose media lacking leucine, histidine, and tryptophan. E, Anti-hemagglutinin Western blot demonstrating that both AvrPto alleles are expressed in yeast. 
(Pedley and Martin 2003). In California, P. syringae infections are primarily confined to the Northern region of the state and disease pressure increases during cool, wet springs. The vast majority of tomato crops grown in California are field-grown processing (canning) tomato cultivars. The top 50 processing cultivars comprise $98 \%$ of the total cultivars planted in California (California Processing Tomato Advisory Board). In 2008, $90 \%$ of the harvested tomato loads were from processing cultivars possessing genetic resistance to $P$. syringae race 0 (California Processing Tomato Advisory Board). The widespread use of cultivars recognizing the avrPto and avrPtoB effectors present in race 0 strains may provide strong selective pressure to overcome Pto-mediated resistance within P. syringae bacterial populations. Other microbial pathogens have been shown to overcome race-specific resistance by effector deletions, rearrangements, and mutations (Arnold et al. 2007).

We investigated the prevalence and function of both avrPto and $a v r P t o B$ within California strains. We were able to identify a novel avrPto allele, avrPto ${ }_{838-16}$, that is present, expressed, and secreted in four strains (Fig. 3). AvrPto ${ }_{838-16}$ could not interact with tomato Pto by yeast two-hybrid analysis or elicit Pto-mediated resistance, because of a key amino acid polymorphism in the GINP loop where the glycine residue present in the DC3000 allele corresponds to a glutamic acid residue present in the 83816 allele (Fig. 5A). This region has been shown to make direct contact with Pto by structural analyses (Xing et al. 2007). Interestingly, the avrPto $_{316}$ allele, which was isolated from a race 0 isolate, retains the GINP loop but is otherwise identical to avrPto $_{838-16}$. A second race 0 isolate did not possess avrPto but did possess a T1-like $a v r P t o B$ allele. Our molecular phylogenetic data indicate that the majority of $P$. syringae strains isolated in California are very closely related and cluster with $P$. syringe T1 (Fig. 2). These results support the hypothesis that race 1 strains recently evolved from existing $P$. syringae populations. In order to overcome Pto-mediated resistance, it is likely that all $P$. syringae populations would need to alter their expression of AvrPtoB but only some would either need to loose the avrPto gene completely or mutate avrPto in order to evade Pto-mediated recognition.

Growth curve analyses with avrPto $_{838-16}$ demonstrated that this effector can still function to enhance $P$. syringae virulence (Fig. 6). These data indicate that $P$. syringae was able to alter AvrPto's amino acid sequence to overcome Pto-mediated resistance without a commensurate decrease in virulence. Similar results were found in a site-directed mutagenesis screen of the avrPto effector, where selected mutations could uncouple virulence and avirulence properties (Shan et al. 2000). These results are also similar to what was found with $X$. campestris avrBs 2 alleles isolated from resistant pepper genotypes. Gassmann and colleagues (2000) found that naturally occurring $a v r B s 2$ alleles with R403P or A410D still retained virulence attributes but were partially compromised in their ability to elicit $B s 2$-mediated resistance. Recently, it has been demonstrated that AvrPto has a second virulence activity, independent of the GINP loop, which is located in the carboxy terminal domain and is phosphorylated in planta (Anderson et al. 2006; Yeam et al. 2009). Phosphorylation of the carboxy terminal domain on S147 and S149 promotes bacterial virulence in an FLS2/BAK1-independent manner (Yeam et al. 2009). Therefore, it is likely that the AvrPto $_{838-16}$ allele can still promote bacterial virulence through its carboxy terminal domain.

We also investigated the prevalence and expression of the avrPtoB effector. AvrPtoB was detected across all $P$. syringae strains (Table 1). DNA sequencing of this locus revealed that it was closely related to $a v r P t o B_{\mathrm{T} 1}$, with only one amino acid polymorphism at the $\mathrm{N}$ terminus of the protein. As with $P$. syringae T1, we could only detect RNA but not protein-level expres- sion of $a v r P t o B_{19}$ in California race 1 strains (Fig. 3). Previously, Lin and colleagues (2006) demonstrated that the genetic background of $P$. syringae $\mathrm{T} 1$ was responsible for inhibiting avrPtoB expression. AvrPtoB $\mathrm{B}_{\mathrm{DC} 3000}$ protein does not accumulate when expressed in $P$. syringae $\mathrm{T} 1 ;$ AvrPtoB $_{\mathrm{T} 1}$ protein only accumulates when expressed in $P$. syringae DC3000 (Lin et al. 2006). Taken together, these data indicate that modulating AvrPtoB expression is a key mechanism used to overcome Ptomediated resistance. Our growth curve analyses on $P$. syringae 19 avrptob knockouts support the hypothesis that $a v r P t o B$ is still delivered at a low level into plant cells (Fig. 4). It will be important to determine whether low-level expression of $a v r P t o B$ in race 1 strains can still inhibit pathogen growth due to weak Pto-mediated resistance under field conditions. Exactly how race 1 strains control the protein-level expression of AvrPtoB remains unknown; however, it is a common mechanism shared among $P$. syringae race 1 strains. It is plausible that altering expression of key bacterial effectors is a conserved strategy employed by multiple bacterial pathogens. Work in P. aeruginosa has revealed that, although effector genes can be retained across multiple clinical strains, their expression during infection can vary dramatically, and increased levels of effector expression correlate with strain aggressiveness (Roy-Burman et al. 2001; Hauser et al. 2002; Schulert et al. 2003). Our investigation of the molecular basis of resistance breakdown in tomato to $P$. syringae highlights the diversity of approaches bacterial pathogens can use to mask effector recognition in plants.

\section{MATERIALS AND METHODS}

Plant materials.

Tomato (S. lycopersicum) Rio-Grande (RG) lines were grown in the greenhouse at $24^{\circ} \mathrm{C}$, with 14 -h days and $60 \%$ relative
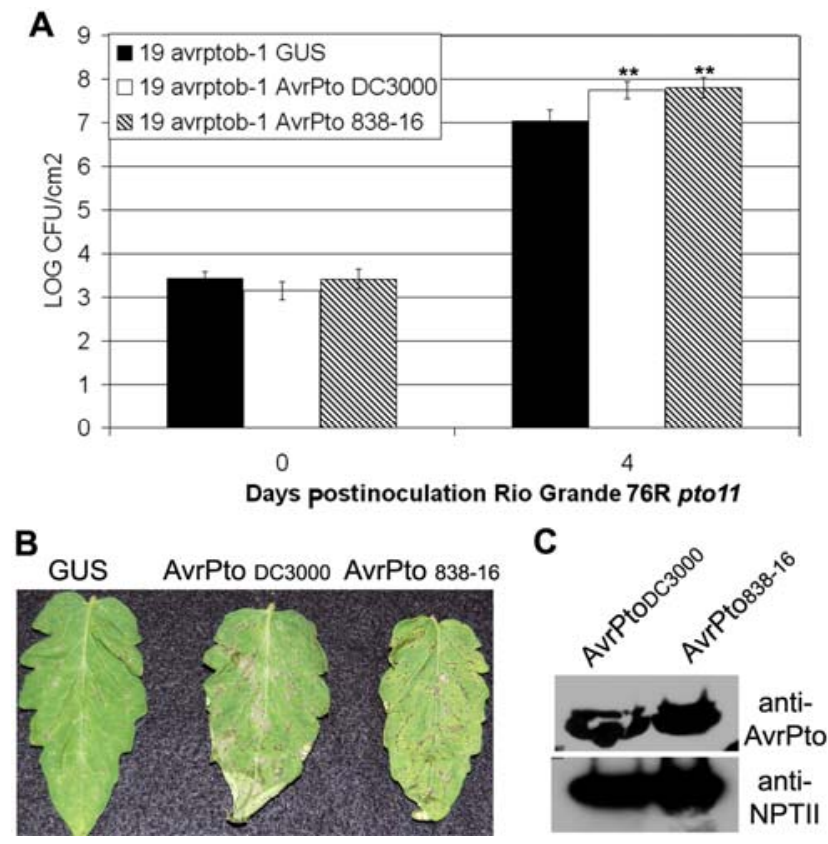

Fig. 6. avrPto $_{838-16}$ allele contributes to Pseudomonas syringae virulence on tomato. A, Expression of avrPto $_{\mathrm{DC} 3000}$ or avrPto $_{838-16}$ from the broad host range vector pBAV226 enhances virulence of the $P$. syringae 19 $\Delta$ avrptob-1 on tomato. Four-week-old Rio Grande 76R pto11 plants were dip inoculated at a concentration of $1 \times 10^{7} \mathrm{CFU} / \mathrm{ml}$ and growth curves conducted 4 days post inoculation. Results are shown as the mean $(n=4)$, including standard deviation. Statistical differences were detected with a two-tailed $t$ test $(\alpha=0.01)$. B, Disease symptoms 4 days post inoculation on Rio Grande 76R pto11. C, Western blot analyses demonstrating that both AvrPto $_{\mathrm{DC} 3000}$ and AvrPto $_{838-16}$ are expressed in P. syringae. 
humidity. For all experiments, 5- to 6-week-old plants were used. Two genotypes were included: RG-76R (Pto/Pto Prf/Prf) and RG-76R pto11 (pto11/pto11 Prf/Prf) (Salmeron et al. 1994).

Arabidopsis Columbia (Col-0) and the rps2-101c/rpm1-3 mutant (Mindrinos et al. 1994; Boyes et al. 1998) derived from Col- 0 were sown in soil and stratified at $4{ }^{\circ} \mathrm{C}$ for 2 days. Plants were grown in a controlled environment chamber at $24^{\circ} \mathrm{C}$ with a photoperiod of $10 \mathrm{~h}$ of light and $14 \mathrm{~h}$ of darkness under a light intensity of $85 \mu \mathrm{E} / \mathrm{m}^{2} / \mathrm{s}$. For all the experiments, 4- to 5week old plants were used.

\section{Bacterial strains and plant inoculations.}

All $P$. syringae strains were grown in KB medium (King et al. 1954$)$ at $30^{\circ} \mathrm{C}$. Escherichia coli $\mathrm{DH} 5 \alpha$ and DB3.1 were used for plasmid maintenance and grown in Luria broth (LB) (Ham et al. 1998) at $37^{\circ} \mathrm{C}$. Agrobacterium tumefaciens $\mathrm{C} 58 \mathrm{C} 1$ was grown in $\mathrm{LB}$ medium at $30^{\circ} \mathrm{C}$. The concentrations of antibiotics used in the selective media were as follows: carbenicillin, $50 \mu \mathrm{g} / \mathrm{ml}$; kanamycin, $25 \mu \mathrm{g} / \mathrm{ml}$; rifampin, $100 \mu \mathrm{g} / \mathrm{ml}$; spectinomycin, $50 \mu \mathrm{g} / \mathrm{ml}$; and tetracycline, $10 \mu \mathrm{g} / \mathrm{ml}$.

All $P$. syringae strains isolated in California were collected from infected tomato plants grown in the field. Infected tomato leaves were surface sterilized in $70 \%$ ethanol for $30 \mathrm{~s}$. Leaf tissue, sampled with a 1-cm hole punch, was ground in $200 \mu \mathrm{l}$ of $10 \mathrm{mM} \mathrm{MgCl}$. Buffer $(10 \mu \mathrm{l})$ was then used to streak onto KB plates (King et al 1954). Single fluorescent colonies were tested for their ability to infect the tomato genotypes RG 76R ptoll and RG 76R as described below. $P$. syringae strains collected in 1996 to 1998 and 2005 were provided by M. Davis (Arredondo and Davis 2000).

P. syringae strains were syringe infiltrated into Arabidopsis leaves as described previously (Liu et al. 2009). Tomato genotypes were dip inoculated for $30 \mathrm{~s}$ in $10 \mathrm{mM} \mathrm{MgCl}$ and $0.008 \%$ Silwett L-77 at a concentration of $1 \times 10^{7} \mathrm{CFU} / \mathrm{ml}$. For growth curves and secretion assays, $P$. syringae strains carried the pDSK519 broad host range vector to confer kanamycin resistance. The concentration of antibiotics used for growth curves was decreased by half. All plant inoculations were conducted with four biological replicates and repeated at least twice.

\section{Coronatine production.}

Coronatine production was measured using a potato tuber assay to detect coronatine-induced hypertrophy as previously described (Coplin and Kado 2001). The P. syringae cor- mutant (Sreedharan et al. 2006) and $P$. syringae T1 were used as negative controls for coronatine production. $P$. syringae DC3000 was used as a positive control. Coronatine assays were repeated twice with identical results.

\section{MLST.}

P. syringae genomic DNA was extracted as previously described (Coplin and Kado 2001) and used to amplify the fragment of housekeeping genes. In total, seven primers (gap1, rpoD, pgi, gyrB, kup, acnB, and gltA) were used for MLST and the primer sequences have been described previously (Yan et al. 2008). Gene fragments were amplified from genomic DNA of $P$. syringae strains and gel purified using a GelElute Extraction Kit (5PRIME Inc., Gaithersburg, MD, U.S.A.). PfuTurbo DNA polymerase was used for PCR amplification (Stratagene, La Jolla, CA, U.S.A.). DNA sequencing chromatograms were reviewed and edited with Vector NTI (Invitrogen, Carlsbad, CA, U.S.A.). Edited sequences were aligned in Vector NTI and trimmed to generate fragments of identical lengths. We also included the DNA sequences from closely related $P$. syringae strains for our MLST analyses (Yan et al. 2008). Analyses of nucleotide substitution and diversity in the bacterial genes were performed with START2 (Jolley et al.
2001). In order to identify distinct sequence types, a number was assigned to each distinct allele within a locus. Each strain was given seven numbers that represented its strain type. A table was prepared (Table 2) and all the alleles were provided allele numbers according to the Plant Associated and Environmental Microbes database. Strains with an identical allele were given the same number. Identical sequence types have identical alleles across all seven housekeeping genes. Concatenated sequences for each sequence type were generated in START2 and the resulting file used for phylogenetic analysis using MEGA4 (Tamura et al. 2007). We used the neighbor-joining method for phylogenetic analyses with bootstrap analysis (1,000 replications). The tree was rooted with $P$. syringae $\mathrm{pv}$. syringae B728A (PsyB728a) as the outgroup.

\section{RT-PCR.}

Bacterial cultures were grown for $16 \mathrm{~h}$ in $5 \mathrm{ml}$ of $\mathrm{hrp}$-inducing liquid minimal media at $17^{\circ} \mathrm{C}$ as previously described (Mudgett and Staskawicz 1999). Total RNA was extracted from bacterial pellets using the TRIZOL reagent (Invitrogen) and subjected to Dnase I digestion. The first-strand cDNA was synthesized by using $5 \mu \mathrm{g}$ of total RNA using random primers with a cDNA synthesis kit (Promega Corp.) in a $20-\mu 1$ reaction. PCR was performed using primers AvrPto $F$ (5'-ATGGG AAATATAGTTGTCG) and AvrPto R (5'-TTGCCAGTTACG GTACGG) or AvrPtoB1492 F (5'-GACGACGCGACGCAAT GCCTT) and AvrPtoB R (5'-TCAGGGGACTATTCTAAAA GCA). 16SrRNA was amplified as an internal control using primers $16 \mathrm{~S} F\left(5^{\prime}\right.$-GCGGCAGGCCTAACACAT) and 16S R (5'-GTTCCCCTACGGCTACCTT).

\section{Immunoblotting.}

Sodium dodecyl sulfate polyacrylamide gel electrophoresis and subsequent immunoblotting were performed according to standard procedures (Harlow and Lane 1988). AvrPto and AvrPtoB immunoblots were performed with affinity purified rabbit polyclonal antisera at a concentration of 1:1,000. Antisera recognizing both proteins were a gift from G. Martin (Lin et al. 2006). NptII immunoblots were performed with rabbit polyclonal antisera at a concentration of $1: 1,000\left(5^{\prime}\right.$ to $\left.3^{\prime}\right)$. Hemagglutinin (HA) immunoblots were performed with mouse monoclonal antisera at a concentration of 1:1,000 (GE Healthcare, Piscataway, NJ, U.S.A.). Secondary goat anti-rabbit or goat antimouse IgG-HRP conjugate (Bio-Rad, Hercules, CA, U.S.A.) was used at a concentration of 1:3,000 for detection via enhanced chemiluminescence (Pierce, Rockport, IL, U.S.A.).

For AvrPto and AvrPtoB expression analyses, bacterial cultures were grown for $16 \mathrm{~h}$ in $5 \mathrm{ml}$ of $\mathrm{hrp}$-inducing liquid minimal media at $17^{\circ} \mathrm{C}$ (Mudgett and Staskawicz 1999). Bacterial pellets were boiled in $100 \mu \mathrm{l}$ of laemmli buffer (Laemmli 1970) to extract total protein. Secreted proteins were precipitated as previously described (Vinatzer et al. 2005).

\section{Yeast two-hybrid analysis.}

The yeast strain AH109, containing the HIS3 and lacZ reporter genes, was used for yeast two-hybrid analyses (Matchmaker; Clontech, Palo Alto, CA, U.S.A.). The coding sequences of $a^{2 v P t o} \mathrm{DC}_{\mathrm{D} 3000}, \mathrm{avrPto}_{838-16}$, and $\operatorname{avrPto}_{838-16}$ (E95G) fragments were obtained by PCR amplification, cloned into the pGADT7 vector (activation domain), and sequence verified. The coding sequence of Pto from $S$. pimpinellifolium was cloned into the pGBKT7 vector and sequence verified. The positive control pGAL4 and the negative control pGBKT7 vector were all transformed into the yeast strain AH109 following the manufacturer's protocol. Protein expression was detected in transformed strains by immunoblotting. Transformants were dilution plated onto yeast potato dextrose agar and synthetic dextrose agar 
lacking leucine/tryptophan/histidine containing $10 \mathrm{mM} \mathrm{3-ami-}$ notriazole. Transformants were also plated onto synthetic dextrose lacking leucine/tryptophan with $\alpha$-galactosidase in the media for blue/white screening. Yeast growth was examined as previously described (Day et al. 2006).

\section{Agrobacterium-mediated transient expression.}

avrPto $_{\mathrm{DC} 3000}$, avrPto $_{838-16}$, and avrPto $_{838-16}(E 95 G)$ were cloned into pMD1 with a C-terminal fusion to the HA epitope using gateway technology. All clones were sequence verified and electroporated into $A$. tumefaciens $\mathrm{C} 58 \mathrm{C} 1$.

A. tumefaciens $\mathrm{C} 58 \mathrm{C} 1$ carrying a gene of interest expressed from the binary vector pMD1 was infiltrated onto $N$. benthamiana leaves at an $\mathrm{OD}_{600}$ of 1.0 as described previously (Day et al. 2005). Leaf disks were harvested $40 \mathrm{~h}$ post inoculation for Western blot analyses. For transient expression in tomato, constructs were infiltrated onto the tomato genotypes Rio Grande 76R and Rio Grande ptoll at an $\mathrm{OD}_{600}$ of 0.1 (Salmeron et al. 1994). Transient expression assays were repeated at least three times with identical results.

\section{Construction of the $P$. syringae $19 \Delta a v r P t o B$ null mutant.}

The spectinomycin $(\mathrm{Sp})$ resistance gene was used to replace the $a v r P t o B$ gene in $P$. syringae 19 by homologous recombination, creating $P$. syringae $19 \Delta a v r p t o b$. A $1.5-\mathrm{kb}$ promoter fragment upstream of the $a v r P t o B$ open reading frame (ORF) (UP) was PCR amplified and cloned into pENTR/D-TOPO creating pEDT (UP). A 1.2-kb fragment downstream of the avrPtoB ORF (DOWN) was PCR amplified and then cloned into pENTR/D-TOPO creating pEDT (DOWN). To create pEDT ( $\triangle a v r P t o B)$, the EcoRI/AscI fragment of pEDT (DOWN) was inserted into the same sites of pEDT (UP), creating pEDT ( $\Delta$ avrptob). Then, a $1.5-\mathrm{kb} \mathrm{Sp}$ cassette was cloned into the $E c o$ RI site between the upstream and downstream sequences in

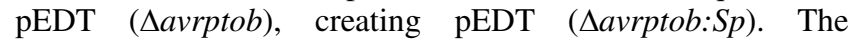
$\Delta a v r p t o b: S p$ fragment was recombined into the suicide vector pLVC18-Rfc (gift from B. Staskawicz's lab) by a Gateway LR reaction (Invitrogen). pLVC18 ( $\Delta a v r p t o b: S p$ ) was moved into $P$. syringae 19 by electroporation. Strains were selected for growth on $\mathrm{KB}$ plates containing $\mathrm{Sp}$ at $50 \mu \mathrm{g} / \mathrm{ml}$ and for loss of growth on KB plates containing tetracycline at $10 \mu \mathrm{g} / \mathrm{ml}$. PCR and sequence analysis confirmed that homologous recombination occurred at the $a v r P t o B$ locus.

$P$. syringae $19 \Delta$ avrptob-1 was used to assess the virulence of avrPto alleles. AvrPto ${ }_{838-16}$, avrPto $_{838-16}$, avrPto $_{\mathrm{DC} 3000}$, and $\beta$ glucuronidase were cloned into the pBAV226 broad host range vector (Vinatzer et al. 2006) using gateway technology and electroporated into $P$. syringae 19 avrptob-1. Growth curves were conducted as described above and repeated twice.

\section{ACKNOWLEDGMENTS}

This work was funded through University of California, Davis startup funds, United States Department of Agriculture National Research Initiative (award 2008-00712) and the hatch project CA-D*-PPA-7757-H to G. Coaker. S. Kunkeaw was funded by the Commission on Higher Education, Thailand. We thank G. Martin for providing antisera recognizing AvrPto and AvrPtoB, M. Davis for providing multiple P. syringae strains collected from 1996 to 2005, D. Mackey for providing rps2-101c/rpm1-3 Arabidopsis seed, R. Michelmore for providing tomato Rio Grande seed, and S. Y. He for providing the $P$. syringae DC3000 coronatine mutant.

\section{LITERATURE CITED}

Abramovitch, R. B., Kim, Y. J., Chen, S., Dickman, M. B., and Martin, G. B. 2003. Pseudomonas type III effector AvrPtoB induces plant disease susceptibility by inhibition of host programmed cell death. EMBO (Eur. Mol. Biol. Organ.) J. 22:60-69.

Abramovitch, R. B., Anderson, J. C., and Martin, G. B. 2006. Bacterial elicitation and evasion of plant innate immunity. Nat. Rev. Mol. Cell Biol. 7:601-611.

Almeida, N. F., Yan, S., Lindeberg, M., Studholme, D. J., Schneider, D. J., Condon, B., Liu, H., Viana, C. J., Warren, A., Evans, C., Kemen, E., Maclean, D., Angot, A., Martin, G. B., Jones, J. D., Collmer, A., Setubal, J. C., and Vinatzer, B. A. 2009. A draft genome sequence of Pseudomonas syringae pv. tomato T1 reveals a type III effector repertoire significantly divergent from that of Pseudomonas syringae pv. tomato DC3000. Mol. Plant-Microbe Interact. 22:52-62.

Anderson, J. C., Pascuzzi, P. E., Xiao, F., Sessa, G., and Martin, G. B. 2006. Host-mediated phosphorylation of type III effector AvrPto promotes Pseudomonas virulence and avirulence in tomato. Plant Cell 18:502-514.

Arnold, D. L., Jackson, R. W., Waterfield, N. R., and Mansfield, J. W. 2007. Evolution of microbial virulence: The benefits of stress. Trends Genet. 23:293-300.

Arredondo, C. R., and Davis, R. M. 2000. First report of Pseudomonas syringae pv. tomato race 1 on tomato in California. Plant Dis. 84:371.

Boyes, D. C., Nam, J., and Dangl, J. L. 1998. The Arabidopsis thaliana RPM1 disease resistance gene product is a peripheral plasma membrane protein that is degraded coincident with the hypersensitive response. Proc. Natl. Acad. Sci. U.S.A. 95 (26):15849-15854.

Chisholm, S. T., Coaker, G., Day, B., and Staskawicz, B. J. 2006. Host-microbe interactions: Shaping the evolution of the plant immune response. Cell 124:803-814.

Coplin, D. L., and Kado, C. I. 2001. A Laboratory Guide for the Identification of Plant Pathogenic Bacteria, 3rd ed., Vol. 1. N. W. Schaad, J. B. Jones, and W. Chun, eds. The American Phytopathological Society, St. Paul, MN, U.S.A.

Day, B., Dahlbeck, D., Huang, J., Chisholm, S. T., Li, D., and Staskawicz, B. J. 2005. Molecular basis for the RIN4 negative regulation of RPS2 disease resistance. Plant Cell 17:1292-1305.

Day, B., Dahlbeck, D., and Staskawicz, B. J. 2006. NDR1 interaction with RIN4 mediates the differential activation of multiple disease resistance pathways in Arabidopsis. Plant Cell 18:2782-2791.

Gassmann, W., Dahlbeck, D., Chesnokova, O., Minsavage, G. V., Jones, J. B., and Staskawicz, B. J. 2000. Molecular evolution of virulence in natural field strains of Xanthomonas campestris pv. vesicatoria. J. Bacteriol. 182:7053-7059.

Göhre, V., Spallek, T., Häweker, H., Mersmann, S., Mentzel, T., Boller, T., de Torres, M., Mansfield, J. W., and Robatzek, S. 2008. Plant patternrecognition receptor FLS2 is directed for degradation by the bacterial ubiquitin ligase AvrPtoB. Curr. Biol. 18:1824-1832.

Goode, M. J., and Sasser, M. 1980. Prevention-the key to controlling bacterial spot and bacterial speck of tomato. Plant Dis. 64:831-834.

Ham, J. H., Bauer, D. W., Fouts, D. E., and Collmer, A. 1998. A cloned Erwinia chrysanthemi Hrp (type III protein secretion) system functions in Escherichia coli to deliver Pseudomonas syringae Avr signals to plant cells and to secrete Avr proteins in culture. Proc. Natl. Acad. Sci. U.S.A. 95:10206-10211.

Harlow, E., and Lane, D. 1988. Antibodies: A Laboratory Manual. Cold Spring Harbor Press., Cold Spring Harbor, NY, U.S.A.

Hauser, A. R., Cobb, E., Bodi, M., Mariscal, D., Valles, J., Engel, J. N., and Rello, J. 2002. Type III protein secretion is associated with poor clinical outcomes in patients with ventilator-associated pneumonia caused by Pseudomonas aeruginosa. Crit. Care Med. 30:521-528.

Huynh, T. V., Dahlbeck, D., and Staskawicz, B. J. 1989. Bacterial blight of soybean: Regulation of a pathogen gene determining host cultivar specificity. Science 245:1374-1377.

Janjusevic, R., Abramovitch, R. B., Martin, G. B., and Stebbins, C. E. 2006. A bacterial inhibitor of host programmed cell death defenses is an E3 ubiquitin ligase. Science 311:222-226.

Jolley, K. A., Feil, E. J., Chan, M. S., and Maiden, M. C. J. 2001. Sequence type analysis and recombinational tests (START). Bioinformatics 17:1230-1231.

Jones, J. D., and Dangl, J. L. 2006. The plant immune system. Nature 444:323-329.

Kim, Y. J., Lin, N. C., and Martin, G. B. 2002. Two distinct Pseudomonas effector proteins interact with the Pto kinase and activate plant immunity. Cell 109:589-598.

King, E., Ward, M. K., and Raney, D. 1954. Two simple media for the demonstration of pyocyanin and fluorescin. J. Lab. Clin. Med. 44:301-307.

Laemmli, U. K. 1970. Cleavage of structural proteins during the assembly of the head of bacteriophage T4. Nature 227:680-685.

Lin, N. C., and Martin, G. B. 2005. An avrPto/avrPtoB mutant of Pseudomonas syringae pv. tomato DC3000 does not elicit Pto-mediated resistance and is less virulent on tomato. Mol. Plant-Microbe Interact. 18:43-51.

Lin, N. C., and Martin, G. B. 2007. Pto- and Prf-mediated recognition of AvrPto and AvrPtoB restricts the ability of diverse Pseudomonas syrin- 
gae pathovars to infect tomato. Mol. Plant-Microbe Interact. 20:806815 .

Lin, N. C., Abramovitch, R. B., Kim, Y. J., and Martin. G. B. 2006. Diverse AvrPtoB homologs from several Pseudomonas syringae pathovars elicit Pto-dependent resistance and have similar virulence activities. Appl. Environ. Microbiol. 72:702-712.

Liu, J., Elmore, J. M., Fuglsang, A. T., Palmgren, M., Staskawicz, B., and Coaker, G. 2009. RIN4 functions with the plasma membrane H+ATPase to regulate stomatal apertures during pathogen attack. PLoS Biol. 7:e1000139.

Maiden, M. C., Bygraves, J. A., Feil, E., Morelli, G., Russell, J. E., Urwin, R., Zhang, Q., Zhou, J., Zurth, K., Caugant, D. A., Feavers, I. M., Achtman, M., and Spratt, B. G. 1998. Multilocus sequence typing: A portable approach to the identification of clones within populations of pathogenic microorganisms. Proc. Natl. Acad. Sci. U.S.A. 95:31403145.

Martin, G. B., Brommonschenkel, S. H., Chunwongse, J., Frary, A., Ganal, M. W., Spivey, R., Wu, T., Earle, E. D., and Tanksley, S. D. 1993. Mapbased cloning of a protein kinase gene conferring disease resistance in tomato. Science 262:1432-1436.

McCann, H. C., and Guttman, D. S. 2008. Evolution of the type III secretion system and its effectors in plant-microbe interactions. New Phytol. 177:33-47.

Mindrinos, M., Katagiri, F., Yu, G. L., and Ausubel, F. M. 1994. The A. thaliana disease resistance gene RPS2 encodes a protein containing a nucleotide-binding site and leucine-rich repeats. Cell 78:1089-1099.

Mucyn, T. S., Clemente, A., Andriotis, V. M., Balmuth, A. L., Oldroyd, G. E., Staskawicz, B. J., and Rathjen, J. P. 2006. The tomato NBARC-LRR protein Prf interacts with Pto kinase in vivo to regulate specific plant immunity. Plant Cell 18:2792-2806.

Mudgett, M. B., and Staskawicz, B. J. 1999. Characterization of the Pseudomonas syringae pv. tomato AvrRpt 2 protein: Demonstration of secretion and processing during bacterial pathogenesis. Mol. Microbiol. 32:927-941.

Nomura, K., Melotto, M., and He, S. Y. 2005. Suppression of host defense in compatible plant-Pseudomonas syringae interactions. Curr. Opin. Plant Biol. 8:361-368.

Pedley, K. F., and Martin, G. B. 2003. Molecular basis of Pto-mediated resistance to bacterial speck disease in tomato. Annu. Rev. Phytopathol. 41:215-243.

Pitblado, R. E., and Kerr, E. A. 1979. A source of resistance to bacterial speck-Pseudomonas tomato. Tomato Genet. Coop. Rep. 29:30.

Pitblado, R. E., and Kerr, E. A. 1980. Resistance to bacterial speck (Pseudomonas tomato) in tomato. Acta Hortic. 100:379-382.

Rivas, L. A., Mansfield, J., Tsiamis, G., Jackson, R. W., and Murillo, J. 2005. Changes in race-specific virulence in Pseudomonas syringae pv. phaseolicola are associated with a chimeric transposable element and rare deletion events in a plasmid-borne pathogenicity island. Appl. Environ. Microbiol. 71:3778-3785.

Roy-Burman, A., Savel, R. H., Racine, S., Swanson, B. L., Revadigar, N. S., Fujimoto, J., Sawa, T., Frank, D. W., and Wiener-Kronish, J. P. 2001. Type III protein secretion is associated with death in lower respiratory and systemic Pseudomonas aeruginosa infections. J. Infect. Dis. 183:1767-1774.

Salmeron, J. M., Barker, S. J., Carland, F. M., Mehta, A. Y., and Staskawicz, B. J. 1994. Tomato mutants altered in bacterial disease resistance provide evidence for a new locus controlling pathogen recognition. Plant Cell 6:511-520.

Salmeron, J. M., Oldroyd, G. E., Rommens, C. M., Scofield, S. R., Kim, H. S., Lavelle, D. T., Dahlbeck, D., and Staskawicz, B. J. 1996. Tomato Prf is a member of the leucine-rich repeat class of plant disease resistance genes and lies embedded within the Pto kinase gene cluster. Cell $86: 123-133$

Sarkar, S. F., and Guttman, D. S. 2004. Evolution of the core genome of Pseudomonas syringae a highly clonal, endemic plant pathogen. Appl. Environ. Microbiol. 70:1999-2012.

Schulert, G. S., Feltman, H., Rabin, S. D., Martin, C. G., Battle, S. E., Rello, J., and Hauser, A. R. 2003. Secretion of the toxin ExoU is a marker for highly virulent Pseudomonas aeruginosa isolates obtained from patients with hospital-acquired pneumonia. J. Infect. Dis. 188:1695-1706.

Scofield, S. R., Tobias, C. M., Rathjen, J. P., Chang, J. H., Lavelle, D. T. Michelmore, R. W., and Staskawicz, B. J. 1996. Molecular basis of gene-for-gene specificity in bacterial speck disease of tomato. Science 274:2063-2065.

Shan, L., He, P., Zhou, J. M., and Tang, X. 2000. A cluster of mutations disrupt the avirulence but not the virulence function of AvrPto. Mol. Plant-Microbe Interact. 13:592-598.

Shan, L., He, P., Li, J., Heese, A., Peck, S. C., Nurnberger, T., Martin, G. B., and Sheen, J. 2008. Bacterial effectors target the common signaling partner BAK1 to disrupt multiple MAMP receptor-signaling complexes and impede plant immunity. Cell Host Microbe 4:17-27.

Snedecor, G., W., and Cochran, W. G. 1980. Chapter 12 in: Statistical Methods, 7th ed. Iowa State University, Ames. IA, U.S.A.

Sreedharan, A., Penaloza-Vazquez, A., Kunkel, B. N., and Bender, C. L. 2006. CorR regulates multiple components of virulence in Pseudomonas syringae pv. tomato DC3000. Mol. Plant-Microbe Interact. 19:768779.

Tamura, K., Dudley, J., Nei, M. and Kumar, S. 2007. MEGA4: Molecular evolutionary genetics analysis (MEGA) software version 4.0. 24:15961599

Tang, X., Frederick, R. D., Zhou, J., Halterman, D. A., Jia, Y., and Martin, G. B. 1996. Initiation of plant disease resistance by physical interaction of AvrPto and Pto kinase. Science 274:2060-2063.

Vinatzer, B. A., Jelenska, J., and Greenberg, J. T. 2005. Bioinformatics correctly identifies many type III secretion substrates in the plant pathogen Pseudomonas syringae and the biocontrol isolate $P$. fluorescens SBW25. Mol. Plant-Microbe Interact. 18:877-888.

Vinatzer, B. A., Teitzel, G. M., Lee, M. W., Jelenska, J., Hotton, S., Fairfax, K., Jenrette, J., and Greenberg, J. T. 2006. The type III effector repertoire of Pseudomonas syringae pv. syringae $\mathrm{B} 728 \mathrm{a}$ and its role in survival and disease on host and non-host plants. Mol. Microbiol. 62:26-44.

Wichmann, G., Ritchie, D., Kousik, C. S., and Bergelson, J. 2005. Reduced genetic variation occurs among genes of the highly clonal plant pathogen Xanthomonas axonopodis pv. vesicatoria, including the effector gene $a v r B s 2$. Appl. Environ. Microbiol. 71:2418-2432.

Wulf, J., Pascuzzi, P. E., Fahmy, A., Martin, G. B., and Nicholson, L. K. 2004. The solution structure of type III effector protein AvrPto reveals conformational and dynamic features important for plant pathogenesis. Structure 12:1257-1268.

Xiang, T., Zong, N., Zou, Y., Wu, Y., Zhang, J., Xing, W., Li, Y., Tang, X., Zhu, L., Chai, J., and Zhou, J. M. 2008. Pseudomonas syringae effector AvrPto blocks innate immunity by targeting receptor kinases. Curr. Biol. 18:74-80.

Xing, W., Zou, Y., Liu, Q., Liu, J., Luo, X., Huang, Q., Chen, S., Zhu, L., Bi, R., Hao, Q., Wu, J. W., Zhou, J. M., and Chai, J. 2007. The structural basis for activation of plant immunity by bacterial effector protein AvrPto. Nature 449:243-247.

Yan, S., Liu, H., Mohr, T. J., Jenrette, J., Chiodini, R., Zaccardelli, M., Setubal, J. C., and Vinatzer, B. A. 2008. Role of recombination in the evolution of the model plant pathogen Pseudomonas syringae pv. tomato DC3000, a very atypical tomato strain. Appl. Environ. Microbiol. 74:3171-3181.

Yang, B., Sugio, A., and White, F. F. 2005. Avoidance of host recognition by alterations in the repetitive and C-terminal regions of AvrXa7, a type III effector of Xanthomonas oryzae pv. oryzae. Mol. Plant-Microbe Interact. 18:142-149.

Yeam, I, Nguyen, H. P., and Martin, G. B. 2009. Phosphorylation of the Pseudomonas syringae effector AvrPto is required for FLS2/BAK1independent virulence activity and recognition by tobacco. Plant $\mathrm{J}$. 61:16-74.

Zhou, J. M., and Chai, J. 2008. Plant pathogenic bacterial type III effectors subdue host responses. Curr. Opin. Microbiol. 11:179-185.

\section{AUTHOR-RECOMMENDED INTERNET RESOURCE}

Plant-Associated and Environmental Microbes database: www.pamdb.org 